\title{
O impacto da pesca do camarão-rosa Farfantepenaeus paulensis (Perez-Farfante) (Decapoda, Penaeidae) nas assembléias de peixes e siris do Parque Nacional da Lagoa do Peixe, Rio Grande do Sul, Brasil
}

\author{
Daniel Loebmann ${ }^{1} \&$ João Paes Vieira ${ }^{2}$ \\ ${ }^{1}$ Departamento de Zoologia, Instituto de Biociências, Universidade Estadual Paulista "Julio de Mesquita Filho". Caixa Postal \\ 199, 13506-970 Rio Claro, São Paulo, Brasil. E-mail: contato@danielloebmann.com \\ 2 Departamento de Oceanografia, Fundação Universidade Federal de Rio Grande. Caixa Postal 474, 96201-900 Rio Grande, \\ Rio Grande do Sul, Brasil. E-mail: docjpv@furg.br
}

\begin{abstract}
The impact of the Pink Shrimp Farfantepenaeus paulensis (Perez-Farfante) (Decapoda, Penaeidae) fishery on the fish and crab assemblages of Lagoa do Peixe National Park, Rio Grande do Sul, Brazil. This work evaluates the impact of the pink shrimp Farfantepenaeus paulensis (Perez-Farfante, 1967) fishery on fish and crab assemblages of Lagoa do Peixe National Park, Brazil. We observed that composition of catches is similar to shrimp fisheries using fyke-net at others estuaries of Rio Grande do Sul State: pink shrimp (53\%), accessory catches (24\%) and bycatch $(23 \%)$. However, fishery composition showed distinct differences along the saline gradient of the main park's lagoon. Regarding only fish species, the most impacted species in this fishery were Brevoortia pectinata (Jenyns, 1842), Micropogonias furnieri (Desmarest, 1823), and Jenynsia multidentata (Jenyns, 1842). In others estuaries from Rio Grande do Sul, in contrast, the most impacted species were M. furnieri, Genidens barbus (Lacepède, 1803) and Genidens genidens (Cuvier, 1829). The potential impact of the pink shrimp fishery at Lagoa do Peixe National Park seemed to be weaker when compared to shrimp fisheries elsewhere. We believe that the decision to prohibit this fishery at the Lagoa do Peixe National Park should not be based on its potential damage to the fish and crab assemblages but based on the simple fact that Brazilian laws do not allow fisheries inside National Parks.

KEY WORDS. Brevoortia pectinata; bycatch; conservation unit management; estuaries; Micropogonias furnieri.
\end{abstract}

RESUMO. Este trabalho avaliou do impacto da pesca do camarão-rosa Farfantepenaeus paulensis (Perez-Farfante, 1967) sobre a assembléia de peixes e crustáceos do Parque Nacional da Lagoa do Peixe. Constatou-se que, em média, a composição nas capturas da pesca do camarão-rosa, com a arte de pesca aviãozinho, é semelhantes àquelas descrita em para outros estuários do Rio Grande do Sul, quando considerada apenas a proporção das grandes categorias analisadas (espécie alvo - camarão-rosa $53 \%$ : captura acessória $24 \%$ : rejeito $23 \%$ ). A composição da fauna acompanhante (captura acessória + rejeito) apresente diferenças pronunciadas ao longo do gradiente salino da laguna. No geral, ao nível específico, as espécies de peixes capturadas com maior intensidade - Brevoortia pectinata (Jenyns, 1842), Micropogonias furnieri (Desmarest, 1823) e Jenynsia multidentata (Jenyns, 1842) - diferem daquelas capturadas em outros estuários do Rio Grande do Sul, onde, além de M. furnieri, os bagres Genidens barbus (Lacepède, 1803) e Genidens genidens (Cuvier, 1829) dominam nas capturas. As estimativas do potencial de impacto das capturas acessório e do rejeito apresentaram valores, do ponto de vista pesqueiro, bastantes satisfatórios, quando comparados com outras artes de pesca do camarão, o que sugere que a decisão de proibir a pesca no Parque Nacional da Lagoa do Peixe não deve ser baseada no impacto da pesca do camarão-rosa sobre a fauna acompanhante, mas sim na atividade pesqueira em si, uma vez que a legislação Brasileira vigente proíbe a pesca dentro de Parques Nacionais.

PALAVRAS-CHAVE. Brevoortia pectinata; estuários; Micropogonias furnieri; manejo de unidades de conservação; rejeito de pesca.

Por mais de um século as pescarias artesanais constituem a base sócio-econômica dos pescadores da região costeira do Rio Grande do Sul. Esta atividade é beneficiada pela presença de estuários que permitem a migração de crustáceos e peixes entre o oceano e as águas continentais, promovendo sua abundância e fácil acesso. No entanto, os pré-requisitos para um efetivo manejo das atividades pesqueiras vêm sendo negligenciados em favor de lucros imediatos (HaImovicl et al. 1998). 
Na captura do camarão-rosa, Farfantepenaeus paulensis (Perez-Farfante, 1967) em estuários do Rio Grande do Sul são utilizadas várias artes de pesca. A legislação vigente (Portaria Sudepe 04, 14/01/86) permite somente artes de pesca passivas como o aviãozinho, embora sejam também utilizadasilegalmente redes de arrasto manual (coca e berimbau ou gerival) e motorizados (prancha ou portas). A proibição das artes de pesca ativa baseia-se na alta proporção em peso de peixes não aproveitados, o que poderia contribuir para um alto impacto desta atividade do ponto de vista econômico e biológico (SAILA 1983, Hudson \& Furness 1988, W assenberg \& Hill 1989, Murray et al. 1992, Alverson et al. 1994, Vieira et al. 1996, Clucas 1997, Branco \& Verani 2006). De fato, os resultados do bycatch da rede aviãozinho apresentados para a Lagoa dos Patos, quando comparados com as redes de arrasto, caracterizam o aviãozinho como uma arte de pesca eficiente e razoavel mente adequada à pesca estuarina e, neste sentido, fundamenta a Portaria Sudepe 04, 14/01/86. No entanto, em termos de número e tamanho de indivíduos capturados os resultados apontam para uma perspectiva menos amena e certamente mais devastadora (VIEIRA et al. 1996).

A criação do Parque Nacional Lagoa do Peixe em 1986 tem causado freqüentes conflitos entre I bama e pescadores residentes. Esses conflitos são conseqüências da legislação atual que proíbe a pesca em Parques Nacionais (Lei dos crimes ambientais 9.605-98 e pelo Decreto-Lei 4340-9.985). No entanto, até o momento não se encontrou solução para esse problema e, a pesca artesanal-profissional com redes do tipo "Aviãozinho", para captura do camarão-rosa F. paulensis, está provisoriamente e excepcional mente autorizada para os pescadores moradores do entorno dessa unidade de conservação (UC).

Apesar das tentativas de ordenar e minimizar os impactos da pesca do camarão-rosa dentro do Parque sabe-se que a seletividade da rede aviãozinho é baixa, capturando outras espécies de crustáceos e peixes acidental mente (VIEIRA et al. 1996). O objetivo deste estudo foi avaliar o impacto da pesca do camarão-rosa nas assembléias de peixes e crustáceos capturados acidentalmente pela rede tipo aviãozinho na Lagoa do Peixe.

\section{MATERIAL E MÉTODOS}

\section{Área de Estudo}

De todos os sistemas estuarinos do Rio Grande do Sul, a Lagoa do Peixe, situada entre as coordenadas $31^{\circ} 26^{\prime} 37,3^{\prime \prime}$; $51^{\circ} 09^{\prime} 44,8^{\prime \prime} \mathrm{W}$ e $31^{\circ} 14^{\prime} 00,8^{\prime \prime}$; $50^{\circ} 56^{\prime} 06,3^{\prime \prime} \mathrm{W}$ (Fig. 1), é o único que apresenta ligação efêmera com o Oceano. Normalmente, sua barra permanece fechada durante os meses de estiagem, acumulando água de banhados e lagoas adjacentes até romperse em direção ao mar (SchwARZBold \& SchäFER 1984). Nos últimos anos, quando a barra não rompe naturalmente, essa é aberta pela intervenção do homem, para a entrada de larvas de camarão-rosa (LoEBMANn \& VieIRA 2005a, b).

A profundidademédia da Lagoa do Peixeéinferior a $50 \mathrm{~cm}$, exceto nos canais e em sua barra, cujas profundidades são superiores a $2 \mathrm{~m}$. O espel ho de água do sistema tem aproximadamen- te 35 km². A localização geográfica da barra, no centro da Lagoa, induz a uma divisão espacial ambiental atípica, quando comparados aos outros estuários do estado do Rio Grande do Sul, pois tanto para o Norte como para o Sul, há presença de uma zona prélímnica (Loebmann \& VieIRA 2005a). Toda a área da Lagoa do Peixe é parte integrante do Parque Nacional da Lagoa do Peixe.

Pescadores locais reconhecem e dividem a Lagoa do Peixe em 13 setores. Seis setores foram previamente escolhidos para amostragem, levando em consideração a viabilidade de amostrar sistematicamente cada setor, e sua representatividade espacial dentro da Lagoa do Peixe. Os setores Chica e Capitão estão localizados ao sul, Paiva e Lagamarzinho, na região centro-norte, e Costa e Véia Terra, ao norte da Lagoa do Peixe (Fig. 1). Cabe ressaltar que a pesca é proibida nos canais profundos e na barra.

\section{Métodos}

O aviãozinho é uma rede cilíndrica com a parte posterior do corpo em forma de funil (saco), onde a panagem é sustentada por aros de ferro. A rede é fixa por estacas em águas rasas de até $2 \mathrm{~m}$ de profundidade (Fig. 2). A pesca é efetuada durante a noite (aproximadamente 12 horas), por meio de atração luminosa (Vieira et al. 1996). O tamanho da malha segue o recomendado pela Portaria do Ibama 09-N/93, que regulamenta $24 \mathrm{~mm}$ de distância entre nós.

Durante a temporada de pesca foram efetuadas coletas diárias, no período de 01/II/2002 a 06/III/2002. Os setores e os pescadores foram aleatoriamente escolhidos, e as despescas foram acompanhadas em tempo integral. Em cada saída, contou-se o número de redes despescadas no bote do pescador voluntário e considerou-se uma amostra como o total do conteúdo de todas essas redes. No desembarque, o pescado era selecionado com base na sua importância comercial e dividido em três categorias (espécie alvo; captura acessória; rejeito de pesca ou descarte) (Alverson et al. 1994).

No próprio local, com a balança dos compradores de camarão, foram mensurados os pesos totais de camarão-rosa, de siris (Callinectes sapidus Rathbun, 1896) e peixes comercializados, assim como do descarte de siri (Callinectes danae Smith, 1869 e dos juvenis de $C$. sapidus). A ictiofauna acompanhante descartada pelos pescadores era levada in natura para a base de estudos da FURG no Farol de Mostardas, onde as espécies foram identificadas, medidas individualmente, contadas e pesadas. Eventual mente exemplares de peixes de grande porte eram medidos e pesados no local.

As estimativas de esforço de pesca e captura total de camarão-rosa foram baseadas em dados fornecidos pelo Ibama, que consistem em: produção diária (kg de camarão-rosa/pescador); esforço diário (número de redes/dia/pescador); e o setor onde a pesca ocorreu. As planilhas foram preenchidas diariamente pelos 165 pescadores credenciados, sendo que a direção do Parque autorizava um máximo de 30 redes para cada pescador, com controle das mesmas por meio de lacres individuais.

Para efeito comparativo os dados coletados foram padronizados e expressos pela captura por unidade de esforço (CPUE)

Revista Brasileira de Zoologia 23 (4): 1016-1028, dezembro 2006 

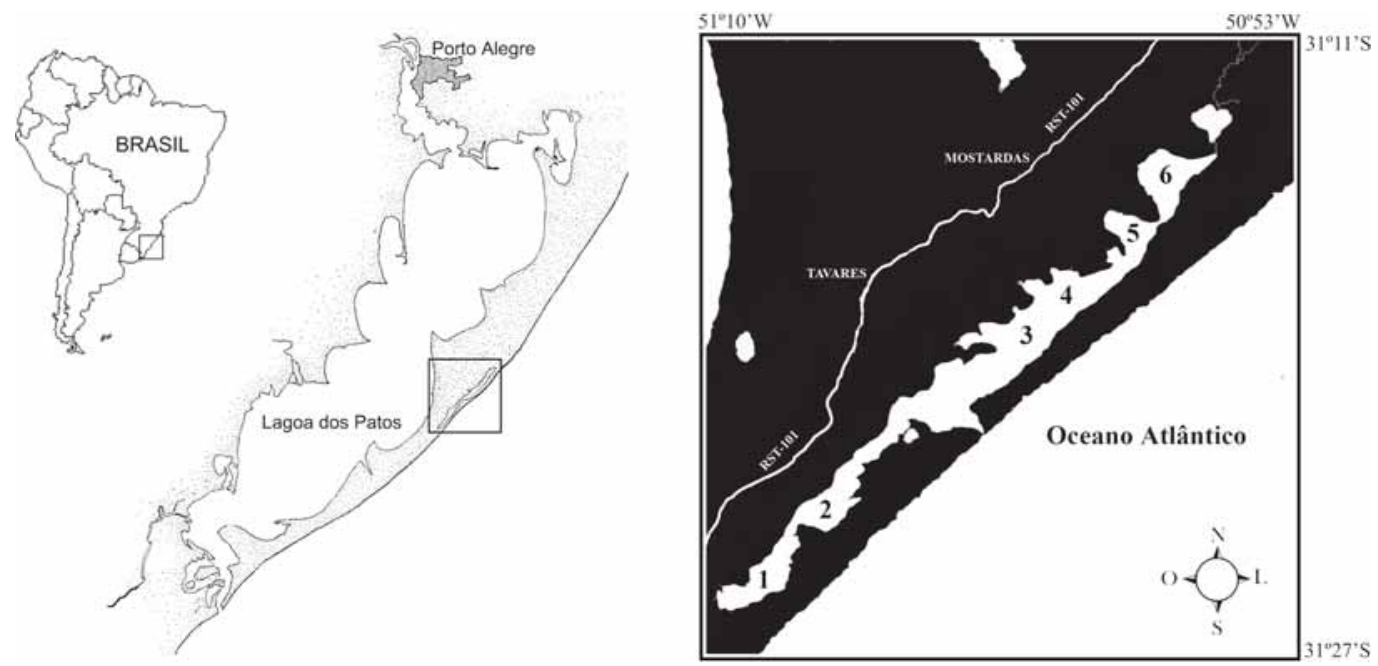

Figura 1. Litoral centro-sul do Rio Grande do Sul com destaque para o Parque Nacional da Lagoa do Peixe e a área de estudo com seus respectivos pontos de coleta: (1) Setor Chica, (2) Setor Capitão-Rosa, (3) Setor Paiva, (4) Setor Lagamarzinho, (5) Setor Costa e (6) Setor Véia Terra.

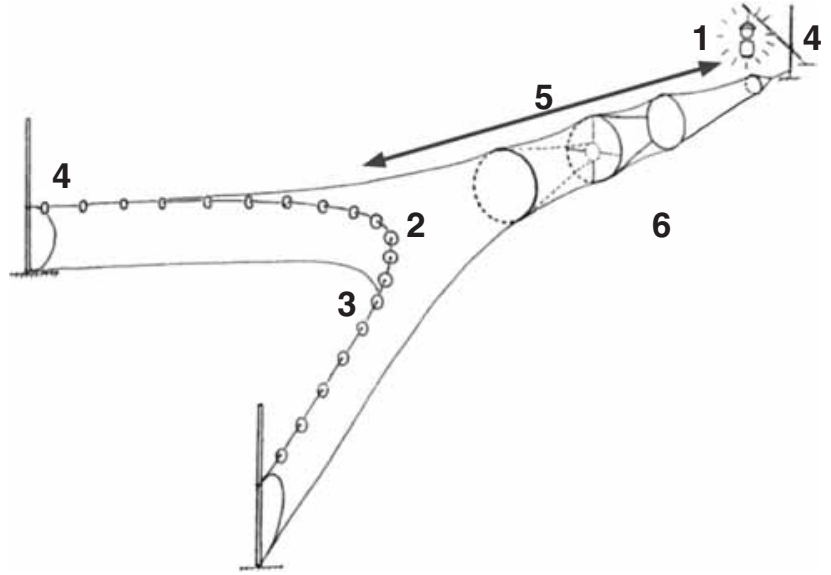

Figura 2. Desenho esquemático da rede de pesca Aviãozinho: (1) atrativo luminoso, (2) tralha superior, (3) tralha inferior, (4) calões de sustentação, (5) saco da rede e (6) aros de sustentação do saco.

que foi calculada a partir da razão entre a captura total, em peso ou em número, e o número redes amostradas, onde: CPUE total = ¿CPUE (espécie alvo + captura acessória + rejeito de pesca).

Diferenças nas CPUEs transformadas (Log10 CPUE+1) foram testadas estatisticamente por ANOVA paramétrica ( $p<$ 0,05 ) e os pressupostos estatísticos (homogeneidade e normalidade) foram testados pelo teste de Kolmogorov-Smirnov e de Cochran, e por representações gráficas (Normal Probability Plot).

Os intervalos de confiança das estimativas foram construídos baseados no método proposto por BucKLAND et al. (1993), indicado para estudos de densidades populacionais. Para cada categoria de pescado foi calculado o valor de " $\mathrm{C}$ " utilizando-se da seguinte expressão $C=\exp \{z a \times d p[\log (y)]\}$, onde za é o valor de t de student e dp é o desvio padrão do $\log _{10} C P U E+1$. Dessa forma, os interval os de confiança gerados são positivos e assimétricos, e são construídos como: $\frac{\mathrm{y}}{\mathrm{C}} \leq \mathrm{y} \geq \mathrm{y} \times \mathrm{C}$, onde $\mathrm{y}$ é a média das CPUEs.

Extrapolações das capturas acessórias e rejeito de pesca (amostragens in situ) sobre o esforço total de pesca (dados do Ibama) foram calculadas para o período estudado. Esse artifício foi utilizado porque as amostragens in situ não avaliavam o esforço de pesca total, e os dados do Ibama não contem informações sobre as capturas acessórias e rejeito de pesca. A viabilidade desse tipo de extrapolação foi testada com análise de variância (ANOVA, p <0,05), sendo que as médias de captura de camarão-rosa dos dois conjuntos de dados, para cada setor, foram comparadas com o teste de contraste de médias (Teste de Tukey) e consideradas iguais quando $p>0,05$.

Foi calculado o Índice de Importância Relativa: IIR\% =FO\% x (PN\% + PW\%), para cada espécie de peixe presente nas amostras. Para as três espécies com os maiores val ores delIR\% - Jenynsia multidentata (Jenyns, 1842), Brevoortia pectinata (Jenyns, 1842) e Micropogonias furnieri (Desmarest, 1823) -, estimou-se a quantidade em peso e em número de indivíduos que foram mortos durante o período estudado. Para essas estimativas se fez necessário calcular a CPUE por classe de comprimento (CPUE-CC) (VIEIRA 2006). Para estas três espécies, baseado nas diferenças de aproveitamento na pesca e nas características populacionais detectadas pela análise de CPUE-CC, foram definidos critérios para avaliar o impacto em cada população. Estimou-se o número de juvenis de $B$. pectinata e $M$. furnieri $(C T<210 \mathrm{~mm}$ ) que chegari-

Revista Brasileira de Zoologia 23 (4): 1016-1028, dezembro 2006 
am a um tamanho de primeira captura pela pesca artesanal $\left(\mathrm{N}_{\mathrm{b}}\right)$, baseado na curva de sobrevivência proposta por GuLLAND (1971) $\left(N_{b}=N_{a} \times e^{-m x t}\right)$. Foram utilizados os índices de mortalidade natural de 0,23 para M. furnieri (Cergole et al. 2005) e 1,1 para B. pectinata, sendo esse último baseado no valor de $M$ de Brevoortia patronus Goode, 1878 (VETter 1988). Utilizou-se o peso médio individual (W) da "idade de primeira captura" de $287 \mathrm{~g}$ para M. furnieri (REIS \& CASTELLO 1996) e de $410 \mathrm{~g}$ para B. pectinata (Haimovici \& Velasco 2000). O produto de $\mathrm{N}_{\mathrm{b}}$ e W geraram o vaIor da biomassa teórica disponível caso os indivíduos não tivessem sido capturados pela pesca do camarão-rosa. Considerou-se que a população de J. multidentata amostrada esteve representada por sua população adulta e esta não é um recurso pesqueiro.

\section{RESULTADOS}

\section{A composição das capturas}

A biomassa total capturada pode ser dividida em cinco itens (Fig. 3). Constatou-se que a espécie alvo (F. paulensis) re presentou $53,9 \%$ do total capturado. A captura acessória foi de $23,6 \%$, podendo ser subdividida em C. sapidus (22\%) e peixes (1,6\%). Dentre os peixes comercializados e/ou não descartados destacam-se: Hoplias malabaricus (Bloch, 1794), Paralichthys orbignyanus Valenciennes, 1839, Rhamdia quelen (Quoy \& Gaimard, 1824), Mugil platanus Gunther, 1880. O restante das capturas $(22,4 \%)$ foi considerado rejeito de pesca, sendo este subdividido em rejeito de crustáceos (dominado por C. danae) $(16,8 \%)$ e rejeito de peixes $(5,6 \%)$, sendo estes compostos por espécies sem interesse comercial ou de pequeno tamanho.

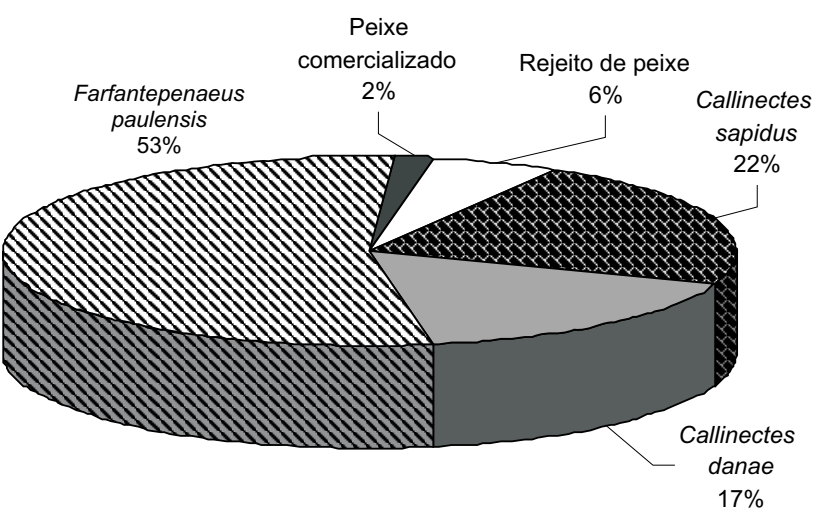

Figura 3. Contribuição relativa, em biomassa, das capturas na rede Aviãozinho.

Para cada setor amostrado observou-se diferenças nas composições e proporções das capturas (Fig. 4), bem como diferenças pronunciadas no esforço (Tab. I), abundância geral (Fig. 5), e produção de camarão-rosa (Fig. 6). Observa-se na figura 4 que a espécie alvo ( $F$. paulensis) foi o item predominante nos setores Paiva, Lagamar e Veia Terra, e Callinectes sapidus (cap-

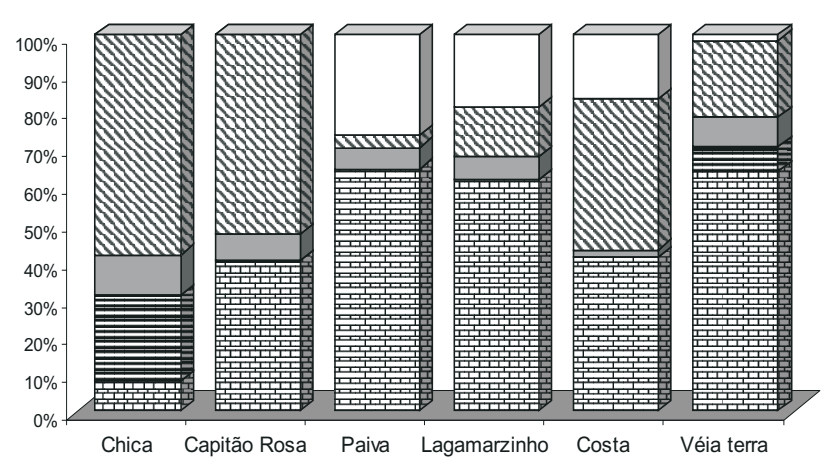

固 Camarão 国 Peixe comercializado $\square$ Rejeito de peixe $\quad$ Siri-Azul $\square$ Siri-Roxo
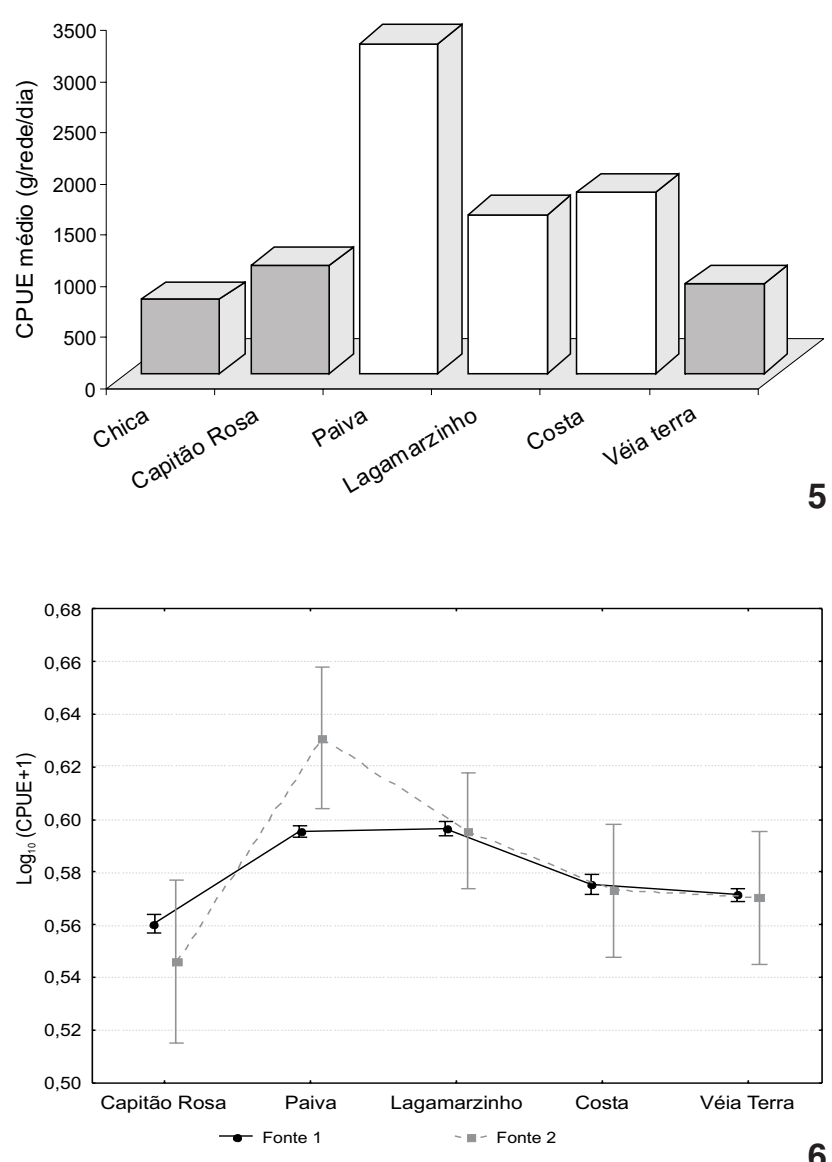

Figuras 4-6. (4) Composição percentual das capturas de cada item analisado para cada setor. Valores baseados na CPUE por setor (g/ rede/dia); (5) captura média total ( $\Sigma$ CPUE espécie alvo + captura acessória + rejeito de pesca (rede/dia)) em gramas para cada setor amostrado. Setores em cinza e em branco equivalem, respectivamente, a região pré-limnica e região estuarina; (6) comparação média das capturas ( $\mathrm{kg} / \mathrm{dia} / \mathrm{rede}$ ) e respectivos intervalos de confiança (I.C. 95\%) entre as fontes de dados (Fonte 1 = Ibama e Fonte 2 = dados amostrados) expressas em $\log _{10} \mathrm{CPUE}+1$. 
Tabela I. Esforço total (número de redes em cada mês por setor ao longo da temporada de pesca) baseado nas planilhas de dados do Ibama.

\begin{tabular}{lrrrrc}
\hline \multicolumn{1}{c}{ Localidade } & Fevereiro & Março & Abril & Maio & Total \\
\hline Chica & 1450 & 660 & & & $2110(1,0 \%)$ \\
Capitão rosa & 9990 & 3230 & 2250 & 400 & $15870(7,9 \%)$ \\
Paiva & 25310 & 22370 & 11520 & 3420 & $62620(31,1 \%)$ \\
Lagamarzinho & 13740 & 27630 & 6080 & 420 & $47870(23,8 \%)$ \\
Costa & 7280 & 9400 & 200 & & $16880(8,4 \%)$ \\
Velha terra & 23880 & 4660 & 240 & & $28780(14,3 \%)$ \\
Diversos locais & 5500 & 9980 & 8940 & 2500 & $26920(13,4 \%)$ \\
\hline Total & 87150 & 77930 & 29230 & 6740 & $201050(100 \%)$ \\
\hline
\end{tabular}

tura acessória) foi o item dominante no setor Chica, Capitão Rosa e Costa. O siri Callinectes danae (descarte) teve uma expressiva contribuição na região estuarina (Paiva, Lagamar e Costa) e peixes de valor comercial foram importantes nos limites sul (Chica) e norte (Velha Terra) da lagoa, estando ausentes nos demais setores. O rejeito de peixes variou de 1,9\% a 10,6\% em todos os setores amostrados.

Padronização entre dados do Ibama e amostragens in situ A comparação entre o esforço de pesca durante o período amostrado (Fonte 2) e durante toda a temporada de pesca (dados do Ibama =Fonte 1) representou 55,2\% do esforço total para estes respectivos setores (Tab. II).

$\mathrm{Na}$ figura 5 podemos observar a produtividade de cada setor ( $\Sigma$ CPUE espécie alvo + captura acessória + rejeito de pesca ( $\mathrm{g} / \mathrm{rede} / \mathrm{dia})$ ). Observa-se que os setores estuarinos (Paiva, Costa e Lagamarzinho) apresentam as maiores produtividades que os setores considerados pré-límnicos (Chica, Capitão-Rosa e Véia Terra) (Loebmann \& VieIRA 2005a).

Na figura 6 observa-se, para os diferentes setores da lagoa, a variação da CPUE do camarão rosa ( $\mathrm{g} / \mathrm{rede} / \mathrm{dia}$ ) calculado com base nos dados do Ibama (Fonte 1) e nos dados amostrados em campo (Fonte 2). Não foram observadas diferenças significati-
Tabela II. Comparação, para o setores analisados, dos esforços de pesca (número de redes vezes dias de pesca) aplicados durante toda a temporada de pesca (Esforço 1, fonte 1 = lbama) e período amostrado (Esforço 2, fonte 2 =dados amostrados), e a contribuição percentual (\%) do total do esforço 2 no esforço 1.

\begin{tabular}{lccc}
\hline \multicolumn{1}{c}{ Setor } & Esforço 1 & Esforço 2 & $\%$ \\
\hline Capitão-rosa & 15870 & 11170 & 70,38 \\
Paiva & 62940 & 30630 & 48,70 \\
Lagamarzinho & 47870 & 19040 & 39,80 \\
Costa & 16880 & 9240 & 54,70 \\
Velha terra & 28780 & 25140 & 87,30 \\
\hline Total & 172340 & 95220 & 55,20 \\
\hline
\end{tabular}

vas ( $p=0,57)$ entre as CPUEs cal culados com os dados das amostragens in situ e dos dados do Ibama, no entanto foram observadas diferenças significativas entre as médias das CPUEs de camarão-rosa para os diferentes setores $(p \approx 0,00)$. Para os dados de campo (Fonte 2 ) o teste de contraste de médias de Tukey apontou valores significativamente maiores para o setor Paiva, em relação aos outros setores. Os setores Lagamarzinho e Costa tiveram médias iguais entre si $(p<0,05)$, assim como os setores Chica, Véia Terra e Capitão-Rosa.

Através do teste de contraste de médias de Tukey, observou-se que os dados de ambas as fontes (amostragens s in situ e dados do Ibama), quando comparados entre setores (Tab. III), são estatisticamente iguais ( $p<0,05$ ), fornecendo suporte estatístico para comparações e extrapolações do rejeito de pesca sobre os dados de esforço de pesca do Ibama.

\section{O esforço de pesca}

As estimativas do esforço de pesca na Lagoa do Peixe, cal culadas com base nos dados fornecidos pelo Ibama, mostraram que os seis setores estudados representam $86,6 \%$ do esforço total de pesca na Lagoa do Peixe (Tab. I). Observa-se na mesma tabela uma estimativa do esforço total de 201050 redes utilizadas na temporada de pesca, o que representou uma mé-

Tabela III. Comparações Post-Hoc (Teste de Tukey) para os setores amostrados: (Cap) Capitão-Rosa, (Pai) Paiva, (Lag) Lagamarzinho, (Cos) Costa e (Vei) Véia Terra, nas duas fontes de dados - Ibama (1) e amostragem in situ (2). Diferenças significativas ( $p<0,05)$ em negrito.

\begin{tabular}{|c|c|c|c|c|c|c|c|c|c|}
\hline & Cap 1 & Cap 2 & Pai 1 & Pai 2 & Lag 1 & $\operatorname{Lag} 2$ & $\operatorname{Cos} 1$ & $\cos 2$ & Vei 1 \\
\hline \multicolumn{10}{|l|}{ Cap 1} \\
\hline Cap 2 & 0,9964 & & & & & & & & \\
\hline Pai 1 & 0,0000 & 0,0580 & & & & & & & \\
\hline Pai 2 & 0,0000 & 0,0020 & 0,2245 & & & & & & \\
\hline Lag 1 & 0,0000 & 0,0488 & 0,9999 & 0,2637 & & & & & \\
\hline Lag 2 & 0,0589 & 0,2352 & 1,0000 & 0,6036 & 1,0000 & & & & \\
\hline $\operatorname{Cos} 1$ & 0,0000 & 0,7093 & 0,0000 & 0,0024 & 0,0000 & 0,7414 & & & \\
\hline $\cos 2$ & 0,9943 & 0,9495 & 0,7780 & 0,0642 & 0,7333 & 0,9470 & 1,0000 & & \\
\hline Vei 1 & 0,0001 & 0,8509 & 0,0000 & 0,0006 & 0,0000 & 0,4819 & 0,7667 & 1,0000 & \\
\hline Vei 2 & 0,9991 & 0,9744 & 0,6426 & 0,0418 & 0,5914 & 0,8976 & 1,0000 & 1,0000 & 1,0000 \\
\hline
\end{tabular}

Revista Brasileira de Zoologia 23 (4): 1016-1028, dezembro 2006 
dia de 1678 redes/dia se considerarmos que a temporada de pesca durou 120 dias. O esforço aplicado na zona estuarina (Paiva e Lagamarzinho) representou 55,0\% do esforço total (Tab. I). Os dois primeiros meses da temporada corresponderam a $82,1 \%$ do esforço total ( 82540 redes/mês), e nos meses de abril e maio observou-se uma queda abrupta no esforço de pesca com 29230 e 6740 redes/mês, respectivamente.

\section{Avaliação da espécie-alvo}

A análise dos dados do Ibama mostrara que a biomassa de F. paulensis capturada na temporada de pesca foi de 181,3 t (Tab. IV). Ao longo dos meses a captura diminuiu constantemente, sendo que os meses de fevereiro e março representaram $45,0 \%$ e $36,7 \%$ do volume total capturado, respectivamente.

Os maiores valores de CPUE para F. paulensis foram observados na região estuarina (Fig. 6), sendo que os registros de captura total de camarão - rosa do Ibama, com exceção do setor Paiva, foram maiores que as estimativas baseadas na amostragem (Fig. 7). Os setores em que se observaram as maiores diferenças foram Paiva e Véia Terra com 32,8 e 11,2 t de diferença entre as estimativas, respectivamente (Fig. 7).

Embora tenha sido observada uma diminuição nas capturas totais com o decorrer da temporada de pesca (Tab. I), as CPUEs em peso não apresentaram médias estatisticamente diferentes ao serem testadas por ANOVA ( $p<0,05)$, para os três primeiros meses de temporada de pesca, tendo média significativamente menor apenas para o mês de maio (Fig. 8).

Avaliação do impacto na população de Callinectes danae

A biomassa total de C. danae nas amostras foi de $427 \mathrm{~kg}$, ou seja, $17 \%$ do volume total capturado (Fig. 3). A CPUE média da espécie foi de em 295,6 g/rede, variando de zero, no setor Capitão-Rosa, até 869,0 g/rede no setor Paiva (Tab. V), o que correspondeu a $58,8 \%$ de toda a captura deste item. Os resultados extrapolados sobre o esforço total sugerem que a biomassa total de $C$. danae, capturada nos setores amostrados, foi na ordem de 22,6 a 56,6 t, com média em 35,4 t (Tab. V).
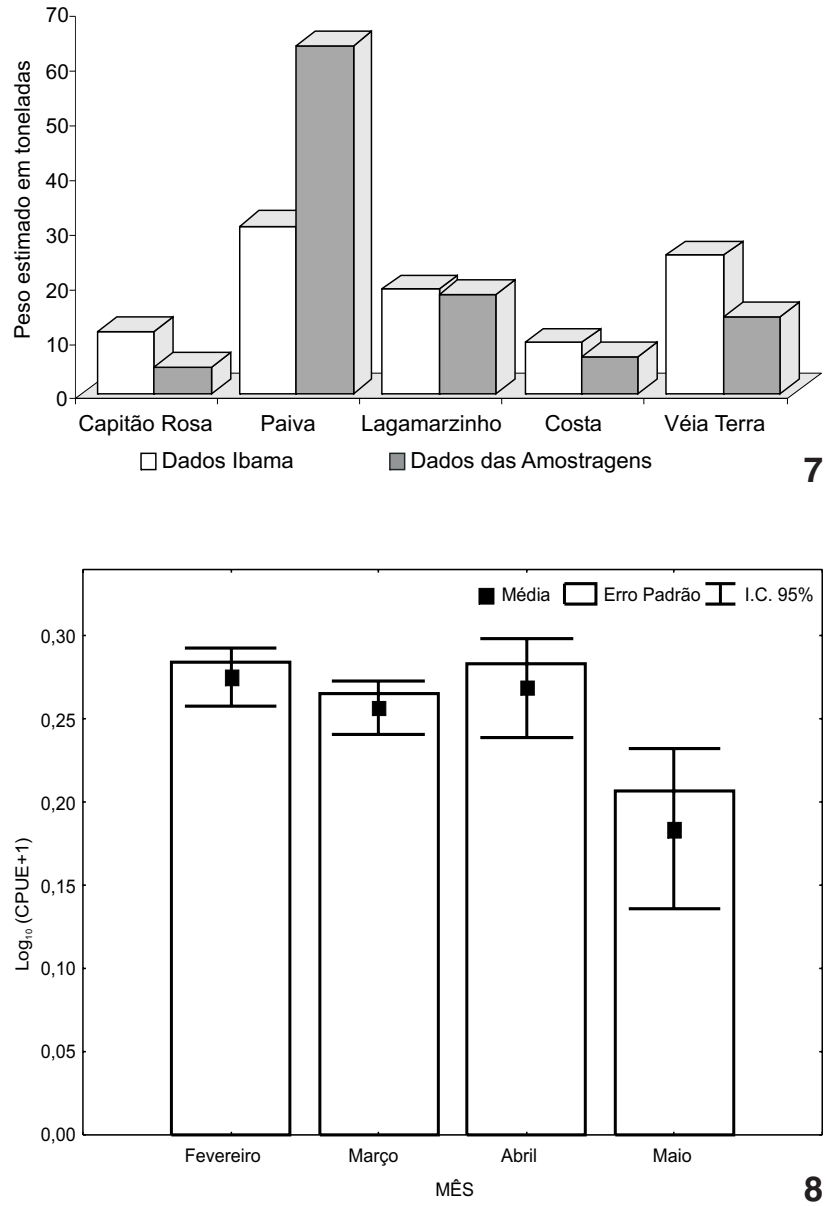

Figuras 7-8. Estimativas da biomassa total de camarão-rosa por setor calculada para os dados do Ibama e para os dados amostrados; (8) Captura média mensal de camarão-rosa expressa em $\log _{10}$ do CPUE ( $\mathrm{kg} / \mathrm{rede} / \mathrm{dia})+1$, com seus respectivos intervalos de confiança $(p>0,05)$ para todos os meses da temporada de pesca.

Tabela IV. Capturas mensais totais de camarão-rosa expressas em quilogramas para cada setor da Lagoa do Peixe. Dados obtidos das planilhas de dados do Ibama. (Dias) Dias de pesca em cada setor.

\begin{tabular}{|c|c|c|c|c|c|c|}
\hline Localidade & Dias & Fevereiro & Março & Abril & Maio & Total \\
\hline Chica & 34 & 698,5 & 360,0 & 0,0 & 0,0 & 1058,5 \\
\hline Capitão rosa & 107 & 7092,5 & 2365,0 & 1485,0 & 158,0 & 11100,5 \\
\hline Formiga & 70 & 895,0 & 1142,0 & 774,0 & 0,0 & 2811,0 \\
\hline Natalicio & 26 & 118,5 & 0,0 & 0,0 & 0,0 & 118,5 \\
\hline Cambota & 120 & 1460,0 & 5905,0 & 5929,0 & 944,0 & 14238,0 \\
\hline Barra & 62 & 0,0 & 3122,0 & 1876,0 & 178,0 & 5176,0 \\
\hline Paiva & 120 & 29730,5 & 17503,2 & 11896,0 & 2101,0 & 61602,7 \\
\hline Lagamarzinho & 97 & 16306,5 & 24564,6 & 3519,0 & 90,0 & 44480,1 \\
\hline Costa & 63 & 5537,5 & 8316,0 & 57,0 & 0,0 & 13910,5 \\
\hline Velha terra & 68 & 18221,2 & 3070,5 & 971,0 & 0,0 & 22262,7 \\
\hline Outras & 90 & 1756,2 & 248,5 & 2738,0 & 149,0 & 4891,7 \\
\hline Total & 120 & 81816,4 & 66596,8 & 29245,0 & 3620,0 & 181650,2 \\
\hline
\end{tabular}


Tabela V. Capturas estimadas totais em quilogramas de cada item analisado para o período amostrado em cada setor, baseadosno produto do intervalo de confiança das amostras in situ (g/rede/dia), gerado pelo método de BucKLAND et al. (1993), pelo esforço de pesca aplicado em cada setor ao longo da temporada de pesca.

\begin{tabular}{|c|c|c|c|c|c|c|c|c|c|}
\hline \multirow{2}{*}{ Item } & \multirow{2}{*}{ Setor } & \multirow{2}{*}{ \# } & \multicolumn{3}{|c|}{ Intervalo de confiança } & \multirow{2}{*}{ Esforço } & \multicolumn{3}{|c|}{ Estimativas } \\
\hline & & & Minimo & Médio & Máximo & & Minima & Média & Máxima \\
\hline \multirow[t]{6}{*}{ Farfantepenaeus paulensis } & Capitão-Rosa & 6 & 226,07 & 396,41 & 695,08 & 11170 & 2525,25 & 4427,89 & 7764,04 \\
\hline & Paiva & 8 & 1408,03 & 2036,88 & 2946,60 & 30630 & 43127,83 & 62389,69 & 90254,32 \\
\hline & Lagamarzinho & 11 & 734,15 & 971,10 & 1284,54 & 19040 & 13978,16 & 18489,81 & 24457,66 \\
\hline & Costa & 10 & 451,37 & 637,03 & 1235,12 & 9240 & 4170,68 & 5886,14 & 11412,51 \\
\hline & Véia Terra & 9 & 393,06 & 571,84 & 831,93 & 25140 & 9881,46 & 14375,94 & 20914,69 \\
\hline & Total & 44 & 642,54 & 922,65 & 1398,65 & 95220 & 73683,38 & 105569,47 & 154803,23 \\
\hline \multirow[t]{6}{*}{ Rejeito de peixes } & Capitão-Rosa & 6 & 41,25 & 89,82 & 195,56 & 11170 & 460,81 & 1003,28 & 2184,37 \\
\hline & Paiva & 8 & 74,98 & 258,23 & 889,37 & 30630 & 2296,52 & 7909,54 & 27241,52 \\
\hline & Lagamarzinho & 11 & 61,98 & 100,82 & 164,00 & 19040 & 1180,15 & 1919,64 & 3122,52 \\
\hline & Costa & 10 & 17,45 & 35,01 & 70,26 & 9240 & 161,23 & 323,54 & 649,25 \\
\hline & Véia Terra & 9 & 26,92 & 63,67 & 150,57 & 25140 & 676,87 & 1600,65 & 3785,21 \\
\hline & Total & 44 & 44,52 & 109,51 & 293,95 & 95220 & 4775,57 & 12756,65 & 36982,87 \\
\hline \multirow[t]{6}{*}{ Peixes comercializados } & Capitão-Rosa & 6 & & 0,00 & & 11170 & 0,00 & 0,00 & 0,00 \\
\hline & Paiva & 8 & & 0,00 & & 30630 & 0,00 & 0,00 & 0,00 \\
\hline & Lagamarzinho & 11 & & 0,00 & & 19040 & 0,00 & 0,00 & 0,00 \\
\hline & Costa & 10 & & 0,00 & & 9240 & 0,00 & 0,00 & 0,00 \\
\hline & Véia Terra & 9 & 6,39 & 54,82 & 470,05 & 25140 & 160,72 & 1378,15 & 11817,10 \\
\hline & Total & 44 & 6,39 & 10,96 & 470,05 & 95220 & 160,72 & 1378,15 & 11817,10 \\
\hline \multirow[t]{6}{*}{ Callinectes sapidus } & Capitão-Rosa & 6 & 346,36 & 557,79 & 898,30 & 11170 & 3868,82 & 6230,56 & 10034,04 \\
\hline & Paiva & 8 & 15,00 & 104,88 & 733,29 & 30630 & 459,47 & 3212,46 & 22460,71 \\
\hline & Lagamarzinho & 11 & 124,30 & 199,83 & 321,25 & 19040 & 2366,76 & 3804,81 & 6116,61 \\
\hline & Costa & 10 & 420,37 & 713,83 & 1212,15 & 9240 & 3884,22 & 6595,77 & 11200,24 \\
\hline & Véia Terra & 9 & 107,80 & 178,83 & 296,65 & 25140 & 2710,09 & 4495,71 & 7457,84 \\
\hline & Total & 44 & 202,77 & 351,03 & 692,33 & 95220 & 13289,34 & 24339,30 & 57269,44 \\
\hline \multirow[t]{6}{*}{ Callinectes danae } & Capitão-Rosa & 6 & & 0,00 & & 11170 & 0,00 & 0,00 & 0,00 \\
\hline & Paiva & 8 & 524,33 & 869,04 & 1440,37 & 30630 & 16060,32 & 26618,75 & 44118,56 \\
\hline & Lagamarzinho & 11 & 229,06 & 295,70 & 381,73 & 19040 & 4361,31 & 5630,17 & 7268,18 \\
\hline & Costa & 10 & 225,35 & 297,97 & 394,01 & 9240 & 2082,20 & 2753,27 & 3640,62 \\
\hline & Véia Terra & 9 & 3,80 & 15,26 & 61,29 & 25140 & 95,54 & 383,68 & 1540,88 \\
\hline & $\overline{\text { Total }}$ & 44 & 245,63 & 295,60 & 569,35 & 95220 & 22599,36 & 35385,88 & 56568,24 \\
\hline
\end{tabular}

\section{Avaliação da captura acessória}

O total de C. sapidus capturado nas amostras foi $494 \mathrm{~kg}$, representando $22 \%$ do total capturado (Fig. 3) e a CPUE média nas amostras foi 351,0 g/rede, variando de 104,9, no setor Paiva, até $713,8 \mathrm{~g} /$ rede no setor Costa (Tab. V). As estimativas de captura de C. sapidus foram de 13,3 a 57,3 t com média em 24,3t (Tab. V).

$\mathrm{O}$ total de peixe com valor comercial capturado não excedeu a $2 \%$ (Fig. 3). O setor Véia Terra foi o único que apresentou esse item (capturas estimadas entre 0,2 a 11,8 t) (Tab. V). Durante as saídas de campo, observou-se que existia um pequeno interesse na compra desse subproduto pelos atravessadores, visto que há dificuldade de comercialização do mesmo.

Avaliação do impacto na ictiofauna rejeitada

A ictiofauna rejeitada foi analisada pela CPUE em número e em biomassa. Constatou-se que a CPUE em biomassa ( $\mathrm{g} /$ rede) da ictiofauna rejeitada foi de $109,5 \mathrm{~g} /$ rede, oscilando entre 35,0 g/rede (Costa) até 258,2 g/rede (Paiva) (Tab. V). 0 número médio de peixes rejeitados por rede foi de $8,7 \mathrm{ind} / \mathrm{rede}$, com valores médios para cada setor oscilando entre $2,1 \mathrm{ind} / \mathrm{rede}$ (Véia Terra) até 14,0 ind/rede (Paiva).

Baseado nos resultados da CPUE média de biomassa de peixes de cada setor, as estimativas de peixes acidentalmente

Revista Brasileira de Zoologia 23 (4): 1016-1028, dezembro 2006 
capturados no período de estudo foi de 12,8 t com valores mínimos e máximos estimados em 4,8 e 37,0 t, respectivamente (Tab. V). As estimativas máximas foram influenciadas pelas grandes flutuações encontradas no setor Paiva, onde se registraram valores de CPUE de 12,4 g/rede até 1599,4 g/rede. As estimativas do número de indivíduos capturados no período amostrado chegaram a um valor médio de 965874 indivíduos para todos os setores amostrados (com exceção ao setor Chica), sendo que as três espécies mais abundantes foram J. multidentata, M. furnieri e B. pectinata (Tab. VI).

\section{A composição da ictiofauna acompanhante e as espécies} potencialmente afetadas

As 48 amostras provenientes de 1632 redes resultaram na captura de 45 espécies pertencentes a 23 famílias de peixes num total de 13988 indivíduos (Tab. VI). Na mesma tabela, observa-se que $\mathrm{B}$. pectinata foi a espécie mais abundante em número, compreendendo $42,5 \%$ dos indivíduos capturados, seguidas por $M$. furnieri $(16,7 \%)$ e J. multidentata (14,6\%). Dos valores totais de biomassa de cada espécie, B. pectinata foi, novamente, a espécie dominante, compreendendo $42,8 \%$ do peso total capturado, seguida por G. brasiliensis (13\%), Hoplias malabaricus (Bloch, 1794) (11,8\%) e M. furnieri (11,5\%) (Tab. VI). As três espécies com os maiores valores de IIR\% foram J. multidentata, B. pectinata e M. furnieri.

As estruturas de tamanho e o impacto sobre as três espécies mais abundantes

As análises das curvas de CPUE por classe de comprimento (CPUE-CC) (Fig. 9) sugerem que as maiores capturas ocorreram entre os comprimentos totais de 60 a $120 \mathrm{~mm}$, representando $77,8 \%$ da captura total, sendo que as três espécies mais importantes (J. multidentata, M. furnieri e B. pectinata) representam juntas $74,8 \%$ da abundância total desta amplitude de comprimentos.

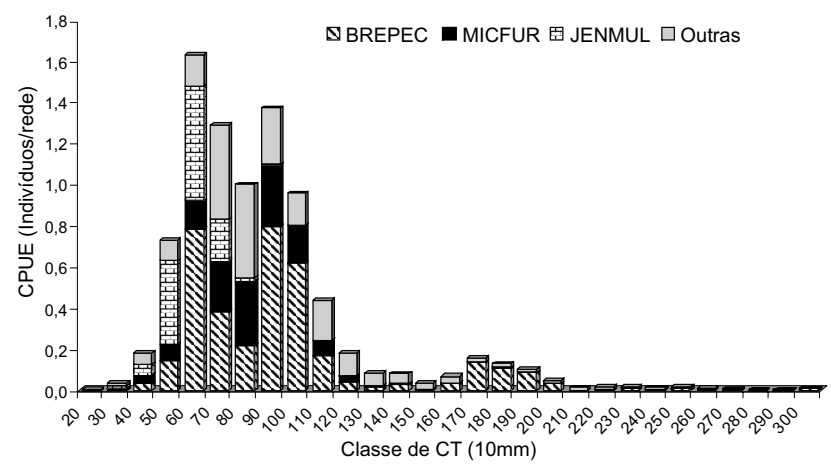

Figura 9. Composição da CPUE (número médio de indivíduos/ rede) por classe de comprimento (10 $\mathrm{mm} \mathrm{CT}$ ) nas capturas para os setores amostrados na Lagoa do Peixe, destacando as três espécies mais importantes. (BREPEC) B. pectinata, (MICFUR) M . furnieri e (JENMUL) J. multidentata.
Jenynsia multidentata foi representada por uma única moda de comprimento entre 50-89 mm CT (Fig. 10). A CPUE médio total foi de $1,00 \mathrm{ind} / \mathrm{rede} /$ dia que multiplicado pelo esforço total no período ( $f=95220$ redes) gera uma captura total estimada para o período de cerca de 95620 indivíduos capturados acidentalmente nesta pescaria. Os valores estimados de biomassa total capturada estão na ordem de 236,5 a $529,5 \mathrm{~kg}$ (Tab. VII), o que representa aproximadamente $0,0002 \%$ das capturas totais estimadas de todos os itens.
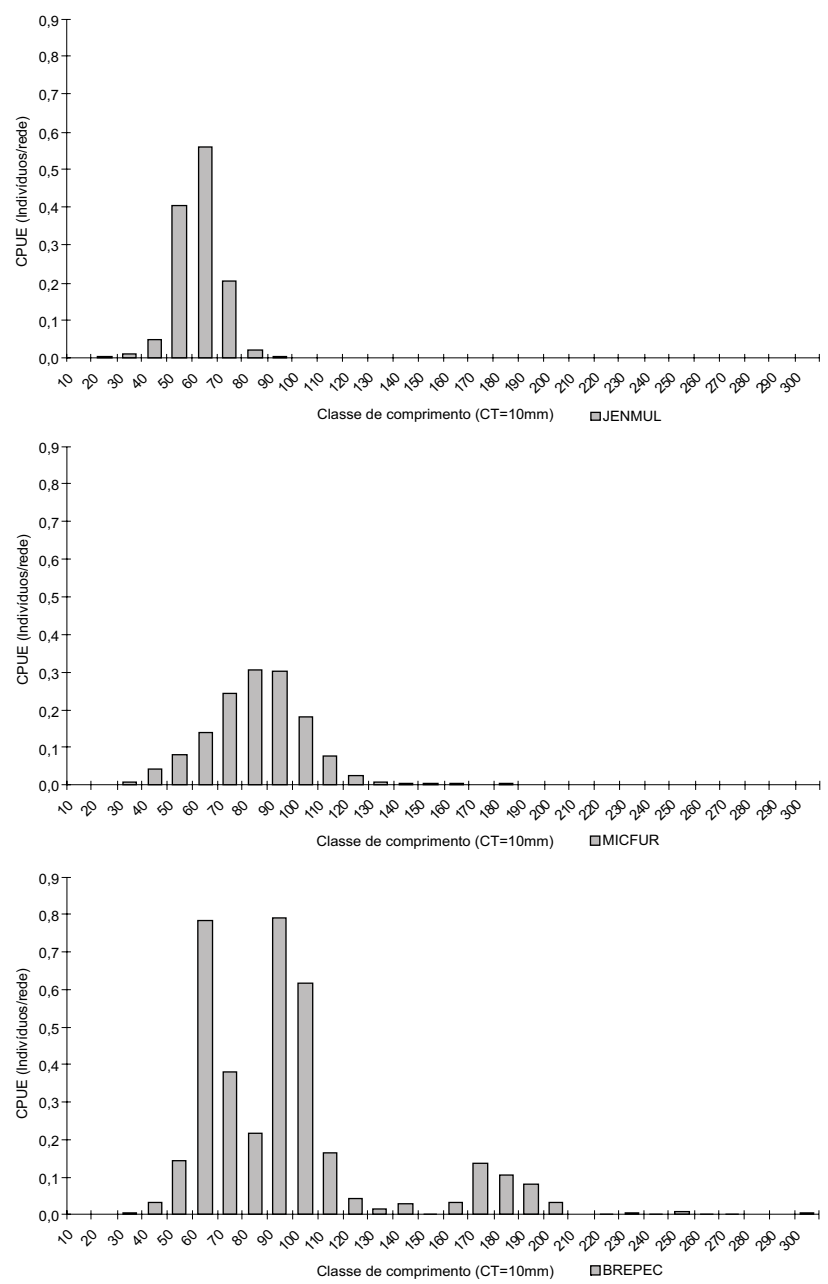

Figura 10. Composição da CPUE (número médio de indivíduos/ rede) por classe de comprimento (10 mm CT) das capturas para os setores amostrados na Lagoa do Peixe de J. multidentata (JENMUL), M. furnieri (MICFUR) e B. pectinata (BREPEC).

No caso de M. furnieri os indivíduos capturados, em sua grande maioria, foram representantes da idade $0(<110 \mathrm{~mm}$ de CT) (Fig. 10) que representam 96,6\% da captura total da espécie. As extrapolações totais para M. furnieri de idade 0 foram na 
Tabela VI. Lista das espécies de peixes encontrada nas redes ao longo das amostragens. (Ntot) Número total de indivíduos coletados; (\%NUM) percentual numérico; (FO) freqüência de ocorrência; (FO\% aj.) freqüência de ocorrência ajustada a 100\%; (W) biomassa capturada; (\% Peso) percentual da biomassa; (IRR\%) índice de importância relativa (IIR\%). Valores maiores que a média geral em negrito.

\begin{tabular}{|c|c|c|c|c|c|c|c|}
\hline Espécie & Ntot & $\%$ NUM & $\mathrm{FO}$ & FO\% aj. & W & $\%$ Peso & IIR \% \\
\hline Brevoortia pectinata (Jenyns, 1842) & 5958 & 42,594 & 33 & 8,049 & 61372,3 & 42,78 & 5869,66 \\
\hline M icropogonias furnieri (Desmarest, 1823) & 2332 & 16,671 & 29 & 7,073 & 16503,2 & 11,50 & 1702,30 \\
\hline Jenynsia multidentata (Jenyns, 1842) & 2041 & 14,591 & 39 & 9,512 & 7475,7 & 5,21 & 1608,95 \\
\hline Geophagus brasiliensis (Quoy \& Gaimard, 1824) & 1055 & 7,542 & 28 & 6,829 & 18717,2 & 13,05 & 1201,09 \\
\hline Odontesthes argentinensis (Valenciennes, 1835) & 740 & 5,290 & 34 & 8,293 & 7197,0 & 5,02 & 730,10 \\
\hline Eucinostomus argenteus Baird \& Girard 1855 & 513 & 3,667 & 29 & 7,073 & 3115,6 & 2,17 & 352,79 \\
\hline Hoplias malabaricus (Bloch,1794) & 129 & 0,014 & 12 & 2,927 & 16866,9 & 11,76 & 294,31 \\
\hline Mugil platanus Günther, 1880 & 362 & 2,588 & 33 & 8,049 & 2314,5 & 1,61 & 288,85 \\
\hline Oligosarcus jenynsii (Günther, 1864) & 137 & 0,979 & 12 & 2,927 & 2174,7 & 1,52 & 62,39 \\
\hline Astyanax eignmanniorum (Cope, 1894) & 240 & 1,716 & 9 & 2,195 & 1144,7 & 0,80 & 47,13 \\
\hline Platanichthys platana (Regan, 1917) & 107 & 0,765 & 23 & 5,610 & 183,5 & 0,13 & 42,78 \\
\hline Gobionellus oceanicus (Pallas, 1770) & 37 & 0,265 & 19 & 4,634 & 461,9 & 0,32 & 23,22 \\
\hline Rhamdia quelen (Quoy \& Gaimard, 1824) & 17 & 0,122 & 10 & 2,439 & 1114,6 & 0,78 & 18,72 \\
\hline Harengula clupeola (Cuvier, 1829) & 36 & 0,257 & 7 & 1,707 & 1018,7 & 0,71 & 14,11 \\
\hline Atherinella brasiliensis (Quoy \& Gaimard, 1824) & 26 & 0,186 & 13 & 3,171 & 230,3 & 0,16 & 9,38 \\
\hline Cyphocarax voga (Hensel, 1870) & 23 & 0,164 & 8 & 1,951 & 498,6 & 0,35 & 8,53 \\
\hline Mugil gaimardianus Desmarest, 1831 & 71 & 0,508 & 4 & 0,976 & 500,0 & 0,35 & 7,13 \\
\hline Trachinotus carolinus (Linnaeus, 1766) & 10 & 0,071 & 7 & 1,707 & 453,2 & 0,32 & 5,65 \\
\hline Hoplosternum littorale (Hancock, 1828) & 2 & 0,922 & 2 & 0,488 & 308,0 & 0,21 & 4,74 \\
\hline Mugil curema Valenciennes, 1836 & 46 & 0,329 & 4 & 0,976 & 241,9 & 0,17 & 4,15 \\
\hline $\begin{array}{l}\text { Hyphessobrycon igueus (Miquelarena, Menni, } \\
\text { Lopes \& Castiotta, 1980) }\end{array}$ & 27 & 0,193 & 4 & 0,976 & 29,3 & 0,02 & 1,78 \\
\hline Cichlasoma facetum (Jenyns, 1842) & 6 & 0,043 & 3 & 0,732 & 129,5 & 0,09 & 0,83 \\
\hline Epinephelus marginatus (Lowe, 1834) & 5 & 0,036 & 4 & 0,976 & 83,7 & 0,06 & 0,78 \\
\hline Lycengraulis grossidens (Agassiz, 1829) & 4 & 0,029 & 3 & 0,732 & 120,3 & 0,08 & 0,70 \\
\hline Sardinella aurita Valenciennes, 1847 & 5 & 0,036 & 1 & 0,244 & 311,0 & 0,22 & 0,53 \\
\hline Cichlasoma portalegrense (Hensel, 1870) & 4 & 0,029 & 3 & 0,732 & 76,2 & 0,05 & 0,51 \\
\hline Pomatomus saltatrix (Linnaeus, 1766) & 4 & 0,029 & 3 & 0,732 & 74,6 & 0,05 & 0,50 \\
\hline Elops saurus Linnaeus, 1766 & 3 & 0,021 & 3 & 0,732 & 75,0 & 0,05 & 0,46 \\
\hline Paralichthys orbignyanus (Valenciennes, 1842) & 1 & 0,007 & 3 & 0,732 & 93,5 & 0,07 & 0,45 \\
\hline Crenicichla lepidota Heckel, 1840 & 2 & 0,014 & 2 & 0,488 & 100,4 & 0,07 & 0,35 \\
\hline Corydoras paleatus (Jenyns, 1842) & 5 & 0,036 & 4 & 0,976 & 6,8 & 0,00 & 0,34 \\
\hline Trachinotus marginatus Cuvier, 1832 & 4 & 0,029 & 3 & 0,732 & 12,0 & 0,01 & 0,23 \\
\hline Urophycis brasiliensis (Kaup, 1858) & 1 & 0,007 & 1 & 0,244 & 142,7 & 0,10 & 0,22 \\
\hline Pimelodella australis Eigenmann, 1917 & 5 & 0,036 & 2 & 0,488 & 12,9 & 0,01 & 0,19 \\
\hline Phalloptychus januaris (Hensel) & 13 & 0,093 & 1 & 0,244 & 3,6 & 0,00 & 0,20 \\
\hline Selene vomer (Linnaeus, 1758) & 3 & 0,021 & 3 & 0,732 & 10,4 & 0,01 & 0,18 \\
\hline Albula nemoptera (Fowler, 1911) & 2 & 0,014 & 2 & 0,488 & 39,9 & 0,03 & 0,18 \\
\hline M ycteroperca acutirostris (Valenciennes, 1828) & 2 & 0,014 & 2 & 0,488 & 31,0 & 0,02 & 0,15 \\
\hline Genidens genidens (Valenciennes, 1839) & 3 & 0,021 & 1 & 0,244 & 71,2 & 0,05 & 0,15 \\
\hline Citharichthys spilopterus Günther, 1862 & 2 & 0,014 & 2 & 0,488 & 12,7 & 0,01 & 0,10 \\
\hline Pogonias cromis (Linnaeus, 1766) & 1 & 0,007 & 1 & 0,244 & 54,9 & 0,04 & 0,09 \\
\hline Stellifer brasiliensis (Schultz) & 1 & 0,007 & 1 & 0,244 & 52,8 & 0,04 & 0,09 \\
\hline Eleotris pisonis (Gmelin, 1789) & 1 & 0,007 & 1 & 0,244 & 9,5 & 0,01 & 0,03 \\
\hline Uraspis secunda (Poey, 1860) & 1 & 0,007 & 1 & 0,244 & 2,0 & 0,00 & 0,02 \\
\hline Scianidae não identificado & 1 & 0,007 & 1 & 0,244 & 1,0 & 0,00 & 0,02 \\
\hline Total & 13988 & 100 & 410 & 100 & 143449,4 & 100 & 12305,06 \\
\hline
\end{tabular}

Revista Brasileira de Zoologia 23 (4): 1016-1028, dezembro 2006 
ordem de 166160 indivíduos capturados no período estudado (Tab. VII). Ao aplicarmos a taxa de mortalidade para M. furnieri $(M=0,23)$, temos ao final de dois anos, período no qual esta espécie passa a ter tamanho de interesse comercial, que o número total de indivíduos restantes estaria entre 59610 e 172593. Extrapolando estas estimativas para o peso médio de M. furnieri com dois anos de idade ( $287 \mathrm{~g}$ ) temos então que a biomassa potencial total seria de 17,1 a 49,3 t (Tab. VII). Esses valores, quando comparados com as estimativas totais de captura da pesca do camarão-rosa passam a representar aproximadamente $13 \%$ da captura total (Fig. 11).

A representação gráfica da CPUE-CC (Fig. 10) da B. pectinata mostrou três modas de comprimento. As duas primeiras modas (60-70 mm e 90-110 mm) podem ser consideradas como indivíduos de idade 0 ( $<119 \mathrm{~mm}$ de CT) e representam as classes de maior captura. Estima-se que a captura total da idade 0 é de 418796 indivíduos o que corresponde à cerca de 88,3\% do total capturado para a espécie (474341 indivíduos) (Tab. VII). A terceira moda (160-199 mm de CT) foi considerada de idade I e foi menos abundante (51541 indivíduos) correspondendo a cerca de $11 \%$ do total capturado. Foram 4004 indivíduos de idade II (> $200 \mathrm{~mm}$ ) que representaram cerca de $0,8 \%$ do total capturado.

Tabela VII. Estimativas mínimas, médias e máximas baseado em BUCKLAND et al. (1993) para as espécies de peixes mais afetadas na pesca do camarão-rosa. (NEC) Número estimado de indivíduos capturados no período amostrado, (NT-IPC) número teórico de indivíduos que atingiriam a idade de primeira captura, (BPA) biomassa potencial atingida em toneladas.

\begin{tabular}{clccc}
\hline \multirow{2}{*}{ Espécie } & \multirow{2}{*}{ Variáveis } & \multicolumn{3}{c}{ Estimativas } \\
\cline { 3 - 5 } & & Mínima & Média & Máxima \\
\hline J. multidentata & NEIC & 64419 & 95620 & 144280 \\
& NT-IPC & 64419 & 95620 & 144280 \\
& BPA & 0,24 & 0,35 & 0,53 \\
M. furnieri & NEIC & 97750 & 166160 & 283023 \\
& NT-IPC & 59610 & 101328 & 172593 \\
& BPA & 17,11 & 29,08 & 49,53 \\
B. pectinata & NEIC & 195111 & 474341 & 1165068 \\
& NT-IPC & 26145 & 63561 & 156117 \\
& BPA & 10,72 & 26,06 & 64,01 \\
\hline
\end{tabular}

Aplicando a taxa de mortalidade natural para B. pectinata $(M=1,1)$ nos indivíduos de idade 0 , estimou-se que o número total de indivíduos que poderiam chegar à fase comercialmente viável (período no qual a espécie passa ter um peso médio individual de 410 g) é de 19087 até 113977 indivíduos. O mesmo raciocínio, quando aplicado à classe de idade I, resulta em estimativas de 7057 a 42140 indivíduos. A soma das estimativas da classe de idade 0 e idade I, projetadas para a classe de idade II estão na ordem de 26144 a 156116 indivíduos. Projetando estas estimativas sobre o peso médio individual de $410 \mathrm{~g}$ temos que a biomassa potencial total de B. pectinata afetada, está entre 10,7 a 64,0 t (Tab. VII). Estes valores, quando comparados com as estimativas totais de captura da pesca do camarão-rosa passam a representar $11 \%$ da captura total (Fig. 11).

\section{A composição final das capturas}

As extrapolações de biomassa resultam em uma nova divisão percentual da fauna de peixes e crustáceos capturados na pesca de camarão-rosa na Lagoa do Peixe (Figs 3 e 11). Os peixes capturados perfaziam não mais do que $8 \%$ em peso das capturas (peixes comercializados $=2 \%$; rejeito de peixes $=6 \%$; Fig. 3) e a espécie alvo (F. paulensis) representava 53,9\%. A extrapolação de biomassa dos juvenis de B. pectinata e M. furnieri eleva a contribuição percentual destas duas espécies para $11 \%$ e $13 \%$ da captura total, reduzindo em cerca de $10 \%$ a contribuição percentual da espécie alvo (45\%; Fig. 11).

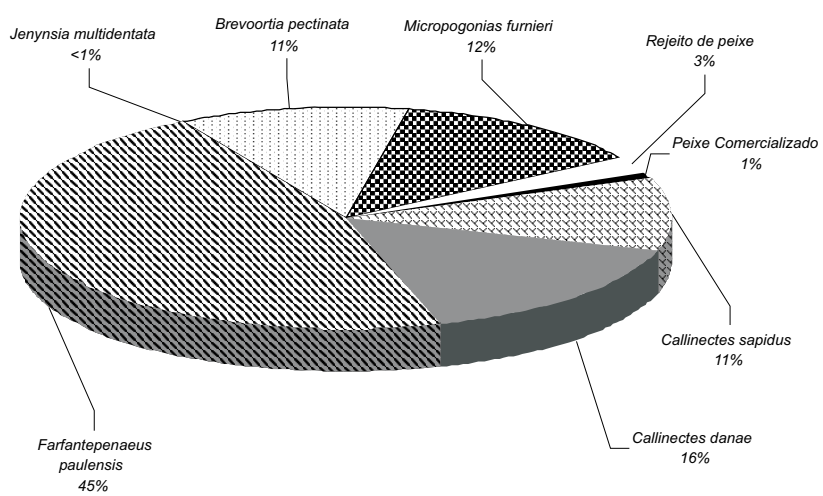

Figura 11. Estimativas finais da abundância relativa em peso dos itens capturados após as extrapolações de biomassa potencial atingida para M. furnieri, J. multidentata e B. pectinata.

\section{DISCUSSÃO}

A contribuição percentual média da espécie-alvo ( $F$. paulensis) capturada pela pesca de camarão-rosa com aviãozinho para a Lagoa do Peixe foi semel hante à observada na Lagoa dos Patos e Tramandaí (VIEIRA et al. 1996), onde as capturas da espécie-alvo geralmente são maiores que $50,0 \%$. Os altos valores percentuais de $\mathrm{F}$. paulensis sugerem que a arte de pesca é bastante seletiva para o camarão, se comparada aos arrastos de fundo utilizados em todo o mundo, onde mais de $80 \%$ das capturas totais são consideradas descartes (Alverson et al. 1994).

É importante ressaltar que, assim como no rejeito da pescaria de arrasto, uma grande parcela do rejeito de peixes capturado pelo aviãozinho é constituída por juvenis (VIEIRA et al. 1996) e, a maioria destes indivíduos, devido ao seu pequeno tamanho, é inviável para o consumo ou a comercialização. Tais capturas são remoções reais do estoque, sendo necessário avaliar os descartes segundo uma ótica que considere a estrutura de tamanho e o número de indivíduos rejeitados, e não simplesmenteo peso capturado (Vieira et al. 1996, Chen \& Gordon 1997). 
Desta forma, a análise dos dados de CPUE-CC por espécie permite um refinamento das estimativas, pois com ela é possível estimar numericamente os indivíduos capturados em cada idade. Esta informação, associada ao cálculo na curva de sobrevivência, permite obter uma estimativa mais aproximada do verdadeiro impacto, uma vez que este cálculo permite avaliar a probabilidade das espécies com potencial pesqueiro deixarem de ser consideradas rejeito de pesca e tornarem-se comercialmente exploráveis.

Jenynsia multidentata é considerada uma espécie freqüente e amplamente distribuída nas lagoas costeiras do Rio Grande do Sul (RAmos \& VieIRA 2001). Ao contrário das outras duas espécies]. multidentata teve suas classes de comprimento representadas pela população adulta, e tal característica nos permitiu concluir que, para esta espécie, a biomassa capturada é igual a biomassa potencialmente impactada. Por não ter interesse comercial J. multidentata não é espécie-alvo nem captura acessória, além disto, seu pequeno tamanho faz com que exista uma sel etividade de captura de indivíduos maiores, dando chance de escape aos indivíduos de comprimentos inferiores a $30 \mathrm{~mm}$. O principal aspecto negativo da captura acidental desta espécie deve-se ao fato de que os indivíduos maiores que $30 \mathrm{~mm}$ geralmente são fêmeas e, considerando que esta espécie é vivípara, muitos destes indivíduos poderiam estar carregando filhotes. De qualquer forma, os resultados encontrados não evidenciaram impacto na população de J. multidentata pela pesca do camarão-rosa na Lagoa do Peixe.

A corvina M. furnieri é considerada um peixe estuarinodependente (VIEIRA et al. 1998), cujos adultos vivem em águas costeiras, sendo que seus estoques são de grande importância econômica nas pescarias do Brasil, Uruguai e Argentina (HAIMOVICl et al. 1997). No estuário da Lagoa dos Patos é a espé cie mais capturada na pesca artesanal (CASTELLO 1986), principalmente a partir dos dois anos de idade (ReIs et al. 1999).

Ao compararmos as estimativas de captura acessória de peixes (11,8 t) com os valores de captura extrapolada para $M$. furnieri $(17,1-49,5 \mathrm{t})$, evidencia-se, a princípio, que a pesca do camarão-rosa apresenta um impacto considerável sobre M. furnieri. No entanto, se considerarmos que as pescarias estuarinas e costeiras de M. furnieri no Rio Grande do Sul capturam, em média, cerca de 14000 toneladas por temporada de pesca (HAImovicl et al. 1997) podemos concluir que os valores estimados de biomassa de $\mathrm{M}$. furnieri potencialmente capturada como rejeito de pesca na Lagoa do Peixe são baixos, uma vez que, na pior das hipóteses, o volume de M. furnieri morto acidentalmente corresponderia a menos de $0,4 \%$ da captura da pesca artesanal do Rio Grande do Sul. Estes valores também são muito baixos quando comparados as 2400 t de rejeito de pesca de corvina estimado para a Lagoa dos Patos (W.M. MARQuES, dados não publicados). Acredita-se, portanto, que a quantidade de M. furnieri capturada na Lagoa do Peixe, ao contrário da Lagoa dos Patos, não têm efeito local sobre o estoque adulto.

Brevoortia pectinata pode ser considerada a espécie mais afetada pela pesca do camarão-rosa da Lagoa do Peixe, tanto em número, como em biomassa. A savelha tem baixo valor comercial no Rio Grande do Sul, no entanto, devido a sua grande captura, é freqüentemente usada na fabricação de farinha de peixe. Esta espécie representou cerca de 15,0\% de todo o desembarque de peixes estuarinos e demersais do Rio Grande do Sul entre os anos de 1975-1994, com uma média de 965,5 t/ano (HAIMovicı et al. 1997). Se considerarmos que a biomassa de B. pectinata, potencialmente afetada pela pesca do camarão-rosa na Lagoa do Peixe, está entre 10,7 a 64,0 t, estima-se que esses val ores correspondem a menos que $7 \%$ do total capturado para a espécie.

Conclui-se, portanto, que a pesca de camarão com a rede aviãozinho na Lagoa do Peixe tem baixo impacto sobre a fauna acompanhante de peixes. Isto se deve ao fato que o volume de captura das espécies mais freqüentes, representadas principalmente por juvenis de peixes de importância comercial, como M. furnieri e B. pectinata, é pequeno quando considerado o tamanho de seus respectivos estoques.

A salinidade da Lagoa do Peixe parece ser o principal fator controlador da composição de captura nas redes. Aproximadamente $50 \%$ dos $35 \mathrm{Km}^{2}$ de área da Lagoa do Peixe podem ser considerados zona estuarina produzindo $71,3 \%$ da CPUE total de camarão-rosa. Com relação aos siris, por exemplo, observa-se que $C$. danae ocorreu em maiores proporções nos setores estuarinos mais próximos da barra da Lagoa do Peixe, com diminuição gradativa em sua abundância quanto mais próximo dos extremos pré-limnicos da lagoa. Já com C. sapidus ocorreu o contrário, diminuindo sua abundância na região estuarina.

Embora C. danae seja um importante recurso pesqueiro em Santa Catarina (Branco \& M ASUnARI 1992), essa espécie não possui interesse comercial na Lagoa do Peixe, pois sua carne não tem um bom aproveitamento segundo os pescadores locais. Por esse motivo é considerado como uma "praga" para os pescadores, devido ao fato que esses siris, assim como C. sapidus, danificam as redes de pesca. A estimativa de captura anual de C. danae para a Lagoa do Peixe foi de 35,4 t, sendo este o primeiro registro específico de abundância relativa para a espécie. Ao contrário de $C$. danae as capturas de $C$. sapidus demonstraram que este recurso, embora indesejável pela maioria dos pescadores, contribui de forma expressiva no orçamento final, podendo, em alguns setores, atingir rendimentos financeiros superiores ao do camarão-rosa.

O Ibama registrou um total de 4180 redes tipo aviãozinho para o Parque Nacional da Lagoa do Peixe. Isto significa que, se todos os pescadores usassem todas as suas redes devidamente registradas em todos os dias da temporada de pesca (em torno de 120 dias), poderíamos supor que o esforço total de pesca seria de 501600 redes por temporada de pesca (4180 redes x 120 dias). No entanto, existem fatores que podem alterar essas estimativas.

Os fatores que subestimaram os cálculos de esforço de pesca foram: 1) Pescadores clandestinos de outras localidades e pescadores locais que não possuem autorização e pescam clandestinamente antes e durante a temporada de pesca; 2) O uso de mais redes que o permitido por pescadores cadastrados; 3 )

Revista Brasileira de Zoologia 23 (4): 1016-1028, dezembro 2006 
O uso, embora em número bastante reduzido quando comparados a outros estuários do Rio Grande do Sul, de redes do Tipo Coca (rede de arrasto manual em forma de saco com atrativo luminoso proibido pela legislação ambiental).

Dentre os fatores que superestimaram os cál culos de esforço de pesca, destacam-se: 1) ao longo da temporada de pesca observou-se que há uma diminuição da abundância de camarão-rosa em certos setores, podendo chegar até uma suspensão da pesca por alguns pescadores em função da escassez da espécie-alvo; 2) diariamente houve casos de pescadores que não colocam suas redes por vários motivos (viagem, doença, manutenção, e outros).

O balanço entre os fatores de aumento ou diminuição do esforço real é difícil de ser atingido, no entanto acredita-se numa tendência de subestimação do esforço. Sendo assim, todos os resultados mostrados aqui dão uma idéia mínima do impacto desta pescaria sobre os recursos naturais envolvidos.

\section{CONSIDERAÇÕES FINAIS}

Muita discussão vem sendo colocada nas reuniões entre - Ibama e pescadores credenciados sobre a pesca no Parque Nacional da Lagoa do Peixe. Um dos pontos principais é o número de redes que devem ser liberadas para a temporada de pesca. Não se sabe ao certo se as 4180 redes/dia devem ser consideradas como um número adequado para a Lagoa do Peixe.

A estimativa de captura total anual de camarão-rosa para a Lagoa do Peixe foi de 181,6 t para 2002. Se compararmos estes valores com o encontrado para a Lagoa dos Patos (VIEIRA et al. 1996), onde a produção anual está na ordem de 2009,0 a 5665,9 t/ano pode-se concluir que a produção na Lagoa do Peixe corresponde a menos de $10 \%$ da produção na Lagoa dos Patos. Uma outra comparação importante com a Lagoa dos Patos é que a produtividade média na Lagoa do Peixe (3221,2 g/rede/ dia) é semel hante aos valores observados para a Lagoa dos Patos (2975,9 g/rede/dia), sugerindo que a produtividade média das duas lagoas seja similar. No entanto, a situação é diferente quanto ao esforço de pesca. Para a Lagoa dos Patos estima-se um esforço de 15866 redes/dia, numa área potencial de pesca de $244,2 \mathrm{~km}^{2}$ (VIEIRA et al. 1996). Estes dados resultam numa estimativa de 65 redes $/ \mathrm{km}^{2}$. Quando comparamos com a Lagoa do Peixe, onde as 4180 redes autorizadas estão sendo usadas em uma área de pesca de aproximadamente $35 \mathrm{~km}^{2}$, concluímos que a densidade de redes estaria na ordem de 119,4 a 139,3 redes $/ \mathrm{km}^{2}$. Este valor corresponde mais de duas vezes a densidade de redes encontrada na Lagoa dos Patos.

O uso da técnica do CPUE-CC, associada às estimativas de mortalidade natural das espécies mais capturadas, permite estimar a biomassa potencial que cada espécie atingiria caso não fosse capturada pela pesca do camarão-rosa no Parque. Com estas novas estimativas a captura relativa de peixes pela redeaviãozinho passa dos 7,2\% inicialmente estimados (peixes comercializados $1,6 \%+5,6 \%$ peixe rejeitado) para uma perspectiva menos animadora de $27,5 \%$ de biomassa potencial estimada $(<0,1 \% \mathrm{~J}$. multidentata $+11,4 \%$ B. pectinata $+12,8 \% \mathrm{M}$. furnieri $+2,6 \%$ outras espécies de peixe rejeitado $+0,6 \%$ Peixe comercializado). Mesmo assim, a proporção de peixes capturados no bycatch da rede aviãozinho, quando comparados com as redes de arrasto de pesca de camarão, caracteriza o aviãozinho como uma arte de pesca eficiente e razoavelmente adequada à pesca estuarina e, neste sentido, fundamenta a Portaria SUDEPE NE 04, 14/01/86.

As projeções finais sugeridas neste trabal ho, embora não tenham sido aplicadas a todas as espécies, dão uma idéia mais aproximada do verdadeiro impacto que esta pesca causa dentro desta UC. Mesmo considerando que o rejeito de peixes passe a ser o segundo item mais afetado nesta pescaria, o valor de $45 \%$ da captura total para a espécie-alvo é satisfatório do ponto de vista pesqueiro. Sendo assim, acreditamos que a proibição da pesca do camarão-rosa dentro do Parque Nacional da Lagoa do Peixe não deve ser baseada no impacto da pesca do camarão-rosa sobre a fauna acompanhante, mas sim na atividade pesqueira em si, uma vez que a legislação Brasileira vigente proíbe a pesca dentro de Parques Nacionais.

A principal questão que fica em aberto é avaliar se a população de F. paulensis, que usa a Lagoa do Peixe como uma das suas zonas de criação, se protegida e preservada, poderia garantir a manutenção do estoque adulto, compensando as retiradas desta espécie em todos os outros estuários do Sudeste-Sul do Brasil. Uma hipótese a se considerar seria a relação dos recrutamentos anuais com fatores ambientais. Diversos trabal hos mostram que a influência de eventos meteorológicos extremos, como o excesso de chuva, associado ao fenômeno de El Niño, e a estiagem, associada ao fenômeno de La Nina, afetam em grande escala a dinâmica dos estuários da região sul do Brasil (GARCIA \& VieIRA 2001, GARCIA et al. 2001, 2004).

Por exemplo, no Estuário da Lagoa dos Patos o excesso de chuva resulta na "limnização" e aumento da vazão de água para fora do estuário, prejudicando o recrutamento do camarão, enquanto que, a estiagem resulta na forte salinização, incrementando as taxas de recrutamento (CASTello \& Moller 1978, GarCIA et al. 2004). Em contrapartida, na Lagoa do Peixe, Iongos períodos de estiagem resultam no fechamento da barra, reduzindo em até $80 \%$ seu espel ho de água. As conseqüências da seca, neste caso, são dramáticas para a fauna de peixes e crustáceos deste frágil ecossistema costeiro, resultando em altas mortalidades e reduções drásticas nos estoques, muito maiores do que aquelas ocasionadas pelo efeito da pesca. Este fato leva a questionar se esta UC poderia funcionar como um verdadeiro local de criação e manutenção de estoques de espécies de interesse comercial.

\section{AGRADECIMENTOS}

Ao Ibama de Mostardas, à Marinha do Brasil, ao CNPq, à CAPES pela concessão da Bolsa de mestrado para o primeiro autor. Aos pesquisadores Carlos E. Bemvenuti, Érica M.P. Caramaschi, Paul G. Kinas, João M. Góes, Ana C.G. Mai, Luciano G. Fisher, Maria Lúcia F. Antunes e aos revisores anônimos. Aos pescadores voluntários do Parque Nacional da Lagoa do Peixe.

Revista Brasileira de Zoologia 23 (4): 1016-1028, dezembro 2006 


\section{REFERÊNCIAS BIBLIOGRÁFICAS}

Alverson, D.L.; M.H. Freeberg; J.G. Pope \& S.A. Murawski. 1994. A global assessment of fisheries bycacth and discards. FAO Fisheries Technical Paper, Rome, 339: 1-233.

Branco, J.O. \& J.R. Verani. 2006. Análise quali-quantitativa da ictiofauna acompanhante na pesca do camarão sete-barbas, na Armação do Itapocoroy, Penha, Santa Catarina. Revista Brasileira de Zoologia, Curitiba, 23 (2): 381-391.

Branco, J.O. \& S. Masunari. 1992. Crescimento de Callinectes danae Smith (Decapoda, Portunidae) da Lagoa da Conceição, Florianópolis, Santa Catarina, Brasil. Revista Brasileira de Zoologia, Curitiba, 9 (1/2): 53-66.

Buckland, S.T.; D.R. Anderson; K.P. Burnham \& J.L. LaAKe. 1993. Distance Sampling: estimating abundance of biological populations. London, Chapman and Hall, 446p.

CASTELLO, J.P. 1986. Distribuicion, crecimiento y maduracion sexual de la corvina juvenil (Micropogonias furnieri) en el estuario de la Lagoa dos Patos, Brasil. Physis, Buenos Aires, 44 (106): 21-36.

Castello, J.P. \& O.O. Moller. 1978. On the relationship between rainfall and shrimp production in the estuary of the Patos Lagoon (Rio Grande do Sul, Brazil). Atlântica, Rio Grande, 3: 67-74.

Cergole, M.C.; A.O. Ávila-da-Silva \& C.L.D.B. Rossi-WongtschowsKı. 2005. Análise das principais pescarias comerciais da região Sudeste-Sul do Brasil: dinâmica populacional das espécies em explotação (Série documentos Revizee: Score Sul). São Paulo, Instituto Oceanográfico USP, 176p.

Chen, Y. \& G.N.G. Gordon. 1997. Assessing discarding at sea using a length-structure yield-per-recruit model. FAO Fisheries Research, Roma, 30: 43-55.

CLUCAS, I. 1997. A study of theoptionsfor utilization of bycatch and discardsfrom marinecapturefisheries. Rome, FAO, 59p.

GarciA, A.M. \& J.P. Vieira. 2001. O Aumento da diversidade de peixes no estuário da Lagoa dos Patos durante o episodio El Nino 1997-1998. Atlântica, Rio Grande, 23: 85-96.

Garcia, A.M.; J.P. Vieira \& K.O. Winemiller. 2001. Dynamics of theshallow-water fish assemblage of the Patos Lagoon estuary (Brazil) during cold and warm ENSO episodes. Journal of Fish Biology, London, 59: 1218-1238.

Garcia, A.M.; J.P. Vieira; K.O. Winemiller \& A.M. Grimm. 2004. Comparison of the 1982-1983 and 1997-1998 El Nino effects onthe shallow-water fish assemblage of the Patos Lagoon estuary (Brazil). Estuaries, Mississipi, 27 (6): 905-914.

GuLLAND, J.A. 1971. Manual de metodos para la evaluacion de las poblaciones de peces. Zaragoza, Ed. Acribia, 164p.

Haimovici, M. \& G. Velasco. 2000. Relações comprimento-peso de peixes teleósteos marinhos do sul do Brasil com uma avaliação de diferentes métodos de ajuste. Atlântica, Rio Grande, 22: 131-140.

Haimovici, M.; J.P. Castello \& C.M. Vooren. 1997. Fisheries, p. 183-196. In: U. Seeliger; J.P. Castello \& C. Odebrecht (Eds). Subtropical convergence environments: the coast and sea in the Southwestern Atlantic. Berlin, Springer-Verlag, 326p.
Haimovici, M.; J.P. Castello \& C.M. Vooren. 1998. Pescarias, p. 205-218. In: U.O.C. Seeliger \& J.P. CAstello (Eds).Os ecossistemas costeiro emarinho do extremo sul do Brasil. Rio Grande, Editora Ecoscientia, 326p.

Hudson, A.V. \& R.W. Furness. 1988. Utilization of discarded fish by scavenging seabirds behind whitefish trawlersin Shetland. Journal of Zoology, London, 215: 151-166.

Loebmann, D. \& J.P. Vieira. 2005a. Distribuição espacial e abundância das assembléias de peixes no Parque Nacional da Lagoa do Peixe, Rio Grande do Sul, Brasil. Revista Brasileira de Zoologia, Curitiba, 22 (3): 667-675.

Loebmann, D. \& J.P. Vieira. 2005b. Composição e abundância dos peixes do Parque Nacional da Lagoa do Peixe, Rio Grande do Sul, Brasil e comentários sobre a fauna acompanhante de crustáceos decápodos. Atlântica, Rio Grande, 27 (2): 131-137.

MurRaY, J.D.; J.J. Bahen \& R.A. Rulifson. 1992. Management considerations for by-catch in the North Carolina and Southeast Shrimp Fishery. Fisheries, Sacramento, 17 (1): 21-26.

Ramos, L. \& J.P. Vieira. 2001. Composição Específica e Abundância de peixes de zonas rasas dos cinco estuários do Rio Grande do Sul, Brasil. Boletim do Instituto de Pesca, São Paulo, 27 (1): 109-121.

ReIS, E.G.; J.P. CASTELLO. 1996. Growth parameters of white croaker (Micropogonias furnieri) derived from length composition. Atlântica, Rio Grande, 18: 101-122.

Reis, E.G.; M.L. Asmus; J.P. Castello \& L.J. Calliari. 1999. Building human capacity on coastal and ocean management implementing the Train-Sea-Coast Programme in Brazil. Ocean and Coastal Management, Oxford, 42: 211-218.

SAILA, S. 1983. Importance and assessment of discards in commercial fisheries. Rome, FAO, 62p.

Schwarzbold, A. \& A. Schäfer. 1984. Gênese das lagoas costeiras do Rio Grande do Sul. Amazoniana, Manaus, 9 (1): 84-104.

Vetter, E.F. 1988. Estimation of natural mortality in fish stocks: a review. Fishery Bulletin, Seathe, 86 (1): 25-43.

VIEIRA, J.P. 2006. Ecological analogies between estuarine bottom trawl fish assemblages from Patos Lagoon, Rio Grande do Sul, Brazil and York River, Virginia, USA. Revista Brasileira de Zoologia, Curitiba, 23 (1): 234-247.

Vieira, J.P.; M.C. Vasconcellos; R.E. Silva \& L.C. Fisher. 1996. A rejeição da pesca camarão-rosa (Penaeus paulensis) no estuário da Lagoa dos Patos, RS, Brasil. Atlântica, Rio Grande, 18: 123-142.

Vieira, J.P.; J.P. Castello \& L.E. Pereira. 1998. Ictiofauna, p. 56-68. In: U. Seeliger; C. Odebrecht \& J.P. Castello (Eds). Osecossistemas costeiro emarinho do extremo sul do Brasil. Rio Grande, Editora Ecoscientia, 326p.

WAssenberG, T.J. \& B.J. Hill. 1989. The effect of trawling and subsequent handling on the survival rates of the bycatch of prawn trawlers in Moreton Bay, Australia. Fishery Research, Shannon, 7: 99-110.

Recebido em 31.V.2005; aceito em 26.IX.2006.

Revista Brasileira de Zoologia 23 (4): 1016-1028, dezembro 2006 